\title{
Factors associated with $\beta$ cell function and changes of $\beta$ cell function along with duration of diabetes among patients with type 2 diabetes
}

\author{
Yang Lihong, Li Jianing, Hao Shujie, Yang Tingting, Meng Meimei, Lou Qingqing \\ (Health Education Department, Traditional Chinese and Western Medicine Hospital, \\ Nanjing, China)
}

\begin{abstract}
Objective: The aim of the multicenter study was to analyze changes of $\beta$ cell function along with duration of diabetes and the association between hypoglycemic therapies, antihypertension therapies, lifestyle factors and $\beta$ cell function among patients with type 2 diabetes. Homeostasis Model Assessment of Beta Cell Function (HOMA- $\beta$ ) was used to evaluate $\beta$ cell function.
\end{abstract}

Methods: From April 2016 to November 2016, patients were enrolled from endocrinology department of Jiangsu Province, He'nan Province, Shanxi Province and Sichuan Province. Selfdesigned case report form was applied to collect data including general information, disease situation, therapy, laboratory examination, blood glucose records in hospital and inpatient's information.

Results: 4815 patients were enrolled in the present study, 1692 patients were from Jiangsu Province. 781 patients were from He'nan Province. 1757 patients were from Shanxi Province and 585 were from Sichuan Province. The mean age of the sample was 49. There were significant differences in fasting serum insulin (FINS), HOMA- $\beta$, fasting blood glucose and $120 \mathrm{~min}$ blood glucose in patients with different durations of diabetes $(P<0.001)$. Along with prolonging of duration, FINS and HOMA- $\beta$ decreased $(P<0.001, P=0.002)$ while blood glucose and 120 min blood glucose increased $(P<0.001)$. Take patients whose diabetes duration $<1$ year as reference, when the duration of diabetes reached 10 years and 19 years, $\beta$ cell function decreased by $13.32 \%$ and $37.91 \%(P<0.001)$ with a $2 \%$ annual rate of decline. Adjusting for age, duration of diabetes, body mass index (BMI), glycosylated hemoglobin $\mathrm{A} 1 \mathrm{c}(\mathrm{HbA} 1 \mathrm{c})$ in regression analysis, sulfonylureas, Dipeptidyl peptidase-4 (DPP4) inhibitors, Angiotensin $\Pi$ receptor antagonist (ARB) affected $\beta$ cell function ( $P=0.002, P=0.008, P=0.034$, respectively).
Adjusting for duration of diabetes, $\mathrm{BMI}, \mathrm{HbA1c}$ in regression analysis, smoking resulted in decreased $\beta$ cell function $(P=$ 0.035).

\section{Conclusions:}

1. With the development of the duration of diabetes, $\beta$ cell function in patients with type 2 diabetes decreased with a $2 \%$ annual rate.

2. Longer duration of diabetes lead to higher levels of fasting blood glucose and $120 \mathrm{~min}$ blood glucose.

3. Sulfonylureas increased $\beta$ cell function deterioration while DPP-4 inhibitors improved $\beta$ cell function in hypoglycemic therapies.

4. In antihypertension therapies, ARB had positive effects on $\beta$ cell function.

5. Smoking lead to $\beta$ cell function decline, it is recommended that type 2 diabetes patients should take a reasonable way to quit smoking to reduce damages of nicotine on $\beta$ cell function.

Key words: type 2 diabetes; $\beta$ cell function; duration of diabetes; hypoglycemic therapies; antihypertension therapies; lifestyle

\begin{tabular}{ccccc}
\multicolumn{5}{c}{ Table 1 Multiple linear regression model of blood glucose treatment and islet $\beta$ cell function } \\
\hline Variable & Coefficient & Std. Error & t-Statistic & Prob. \\
\hline C & 1.515 & 0.242 & 6.265 & $<0.001$ \\
Sulfonylureas & -0.054 & 0.018 & -3.088 & 0.002 \\
DPP-4 Inhibitors & 0.283 & 0.107 & 2.645 & 0.008 \\
\hline
\end{tabular}

Note: Adjust the duration of diabetes, age, BMI and HbAlc.

\begin{tabular}{ccccc}
\multicolumn{5}{c}{ Table 2 Multiple linear regression model of blood glucose treatment and islet $\beta$ cell function } \\
\hline Variable & Coefficient & Std. Error & t-Statistic & Prob. \\
\hline C & 1.773 & 0.152 & 11.637 & $<0.001$ \\
ARB & 0.057 & 0.027 & -2.123 & 0.034 \\
\hline
\end{tabular}

Note: Adjust the duration of diabetes, age, BMI and HbAlc.

Table 3 Unary linear regression model of smoking and islet $\beta$ cell function

\begin{tabular}{ccccc}
\hline Variable & Coefficient & Std. Error & t-Statistic & Prob. \\
\hline C & 1.750 & 0.052 & 33.43 & $<0.001$ \\
Smoking & -0.020 & 0.009 & -2.112 & 0.035 \\
\hline
\end{tabular}
Note: Adjust the duration of diabetes, age, BMI and HbAlc.

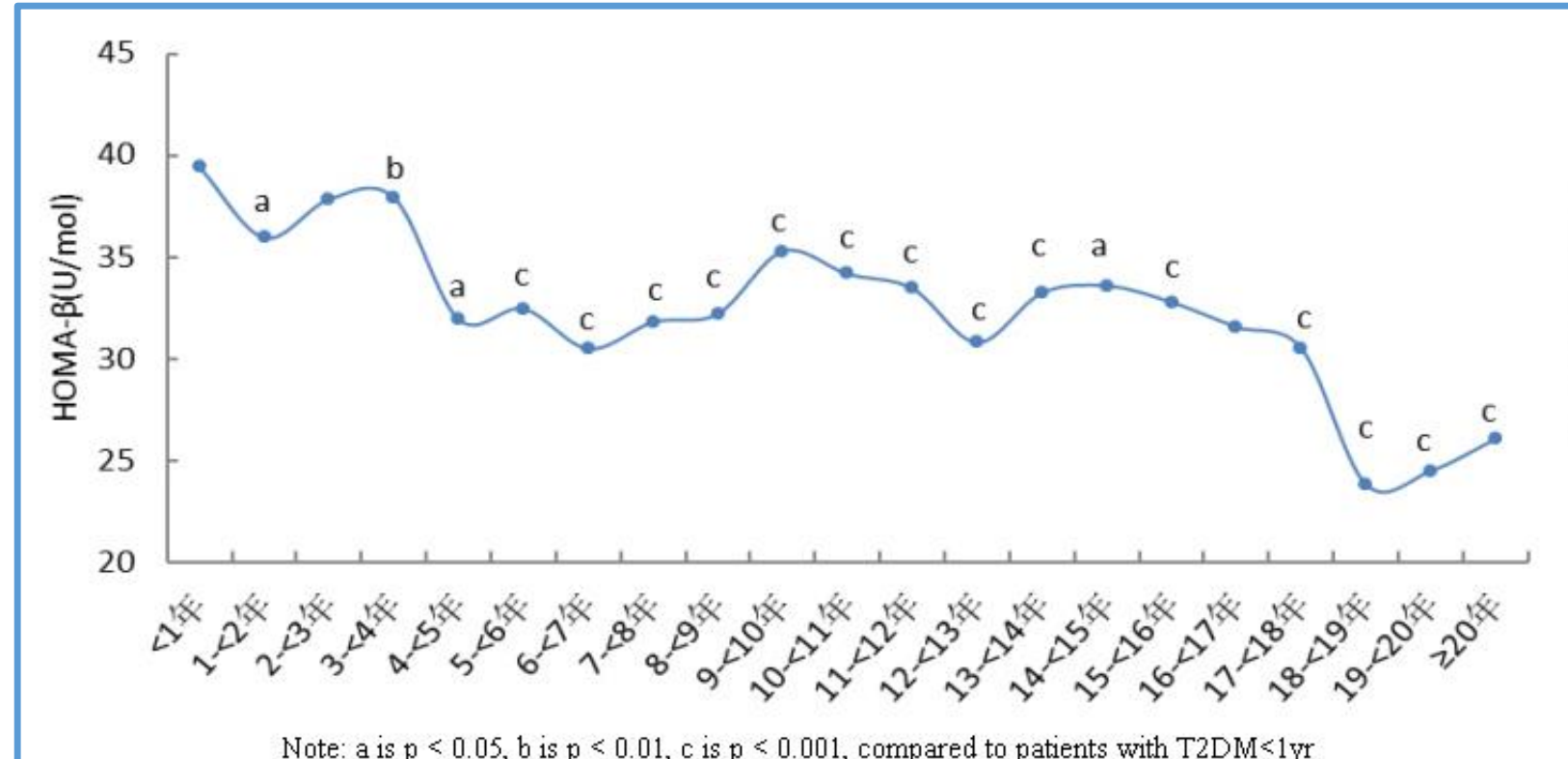

Figure 1 Comparison of HOMA- $\beta$ in T2DM patients with different course of disease

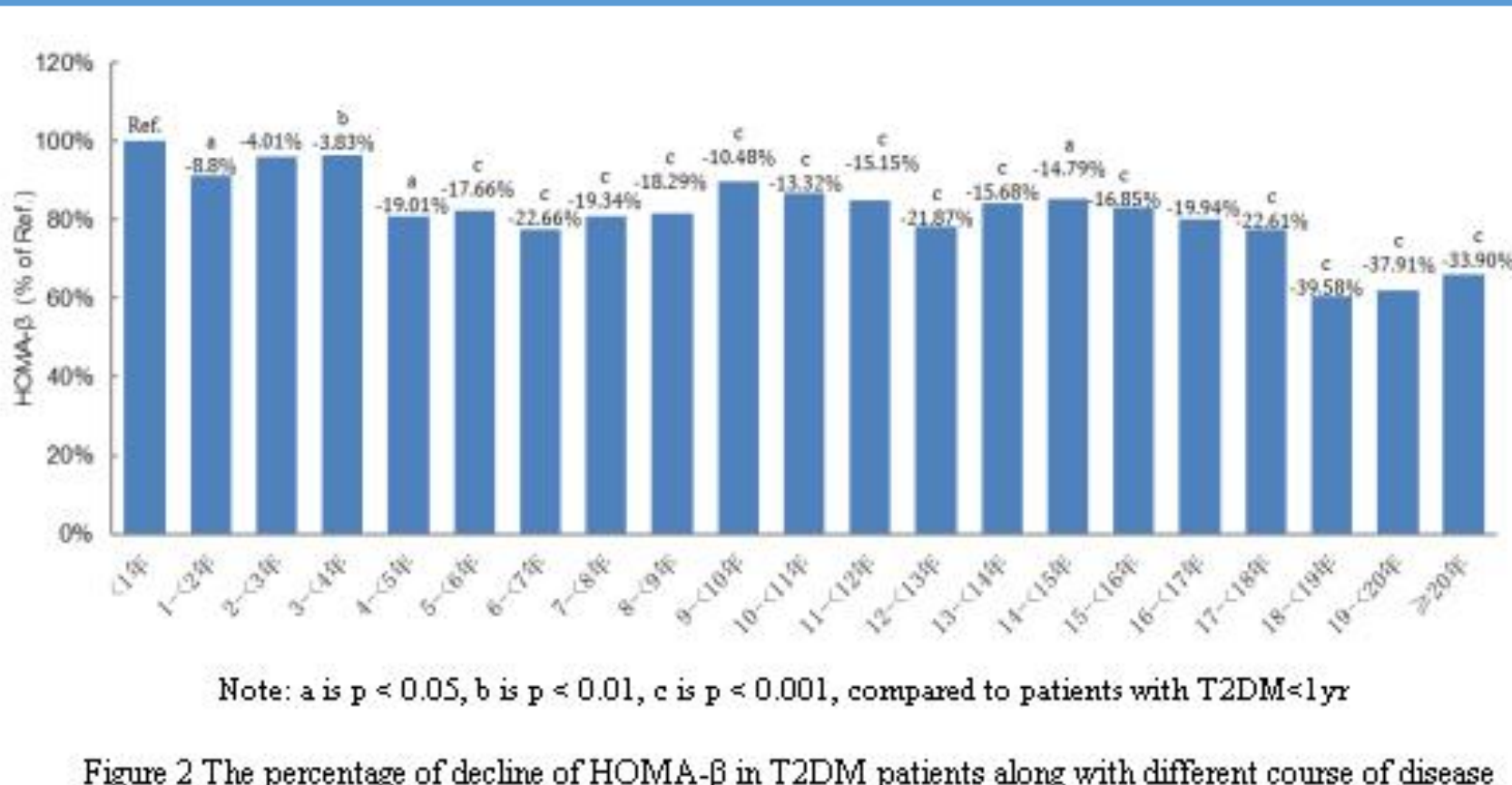

Figure 2 The percentage of decline of HOMA- $\beta$ in T2DM patients along with different course of disease 